\title{
経皮酸素分圧測定による透析患者の末梢循環障害の評価 透析患者の下肢経皮酸素分圧一
}

\author{
紀田康雄瀧秀樹中川浩子江端一彦

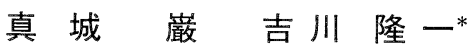 \\ 第二岡本総合病院内科 滋賀医科大学第 3 内科*
}

key words：経皮酸素分圧，透析患者，閉塞性動脈硬化症，末梢循環障害

〈要旨〉

透析患者の下肢末梢循環障害の頻度，虚血の程度を評価するため，65 例の透析患者 (HD 群) と 35 例の性，年齢を マッチした健常対照者（C群）に安静仰臥位で足背の経皮酸素分圧 $\left(\mathrm{TCPO}_{2}\right.$, 単位 $\mathrm{mmHg}$ )を測定し比較した。さら に透析患者での $\mathrm{TCPO}_{2}$ 低下の危険因子を調べた。

1) $\mathrm{TCPO}_{2}$ はC 群と比べ HD群は有意に低值であった $(\mathrm{p}<0.0001) . \mathrm{TCPO}_{2}$ が $50 \mathrm{mmHg}$ 以下の症例は，C群では 2 例（6\%）であったが，HD群では 30 例 $(46 \%)$ と多かった。2） $\mathrm{TCPO}_{2}$ はC 群，HD群ともに年齢とは有意な負の 相関を認めた。また HD 群では糖尿病合併透析患者は非合併例より有意に $T C P O_{2}$ は低かった $\left.(\mathrm{p}<0.01) .3\right) \mathrm{HD}$ 群 のうち糖尿病例では, $\mathrm{TCPO}_{2}$ は RR 間隔変動係数やへモグロビン, 動脈血酸素含量と相関し, 末梢での動静脈シャン トの形成や血液の酸素運搬能低下が $\mathrm{TCPO}_{2}$ 低下の危険因子と考えられた。4） $\mathrm{HD}$ 群の $\mathrm{TCPO}_{2}$ は, Fontaine 2 度以上 の有症状例や末梢動脈の拍動欠損例では低值であったが, 下腿動脈石灰化の有無や上腕足関節血圧比とは相関しな かった.

以上から $\mathrm{TCPO}_{2}$ 測定は簡単で定量的, 非侵襲的な透析患者の末梢循環障害の評価法として有用と考えられた。

\section{Evaluation of peripheral vascular disease in hemodialysis patients using transcutaneous oximetry}

Yasuo Kida, Hideki Taki, Hiroko Nakagawa, Kazuhiko Ebata, Iwao Mashiro, Ryuichi Kikkawa* Daini-Okamoto General Hospital ; Third Department of Medicine, Shiga University of Medical Science*

To investigate the frequency and severity of peripheral vascular disease in hemodialysis patients, we determined transcutaneous oxygen tension $\left(\mathrm{TCPO}_{2}\right)$ as a marker of foot ischemia at rest in the supine position in 65 hemodialysis patients (group HD) and 35 sex and age-matched healthy controls (group C). The factors influencing $\mathrm{TCPO}_{2}$ were also analyzed.

1) $\mathrm{TCPO}_{2}$ in group $\mathrm{HD}$ was significantly lower than in group $\mathrm{C}(\mathrm{p}<0.0001) . \mathrm{TCPO}_{2}$ was less than $50 \mathrm{mmHg}$ in only 2 group $\mathrm{C}$ subjects (6\%) but in $30 \mathrm{HD}$ subjects (46\%).2) In both groups, a significant negative correlation was observed between $\mathrm{TCPO}_{2}$ and age. In group $\mathrm{HD}, \mathrm{TCPO}_{2}$ in diabetics was significantly lower than in non-diabetic subjects $(p<0.01) .3)$ In diabetic $\mathrm{HD}$ subjects, a significant correlation between $\mathrm{TCPO}_{2}$ and the $\mathrm{R}-\mathrm{R}$ interval variation, hemoglobin and arterial $\mathrm{O}_{2}$ content suggested that the development of peripheral arteriovenous shunting and reduced oxygen supply could be risk factors for $\mathrm{TCPO}_{2}$ reduction. 4) $\mathrm{TCPO}_{2}$ in $\mathrm{HD}$ subjects with intermittent claudication, rest pain, and/or skin ulcers was significantly lower than in subjects without these symptoms. But $\mathrm{TCPO}_{2}$ did not correlate with the ankle/brachial pressure index or arterial calcification.

These results indicate that measurement of $\mathrm{TCPO}_{2}$ is a simple, noninvasive, and quantitative technique for assessing peripheral vascular disease in hemodialysis patients.

紀田 康雄 第二岡本総合病院内科 干 611 宇治市神明石塚 54-11(0774-44-4511)

〔受付：平成 5 年 8 月 27 日, 受理：平成 5 年 10 月 21 日) 


\section{緒言}

経皮酸素分圧 $\left(\mathrm{TCPO}_{2}\right)$ 測定は，センサーを皮膚に両 面テープで固定するだけで，局所皮膚㧍よび皮下組織の 虚血に関する定量的な情報を提供してくれる. 本検査法 は血管外科や内科領域でも有用性の確立された方法であ $る^{1-5)}$. 我々も糖尿病患者の下肢虚血の評価法として $\mathrm{TCPO}_{2}$ 測定の有用性を報告するとともに，基準值として $50 \mathrm{mmHg}$ が適当であることを報告してきた ${ }^{6,7)}$. 健常成 人では動脈血酸素分圧と $\mathrm{TCPO}_{2}$ 較差は $20 \sim 30 \mathrm{mmHg}$ であるが，動脈閉塞による血流低下や細動脈-静脈吻合 (AV shunt) の発達などで毛細血管を介する有効血 低下すると，組織への酸素供給が低下し酸素分圧較， 開大し $\mathrm{TCPO}_{2}$ は低下する。今回は $\mathrm{TCPO}_{2}$ を用いてれ, 广 患者の末梢循環障害 (PVD) の頻度を調べるとともに, 透析患者の $\mathrm{TCPO}_{2}$ 低下に関与する因子を検討した。

\section{対象および方法}

対象は第二岡本総合病院透析室で透析を行っている透 析患者 (HD 群) 65 例 (男 39, 女 26 例, 年齢 $58 \pm 14$ 歳) である.また $\mathrm{TCPO}_{2}$ の正常コントロールとして, 健常者 (C群) 34 例（男 18, 女 16 例, 年齢 $58 \pm 20$ 歳）を対照 群とした. $\mathrm{HD}$ 群の透析期間は $4.7 \pm 4.4$ 年, 肥満指数 (BMI) $20.1 \pm 2.7 \mathrm{~kg} / \mathrm{m}^{2}, \mathrm{BUN} 82 \pm 15 \mathrm{mg} / \mathrm{d} l$, Cr $11.4 \pm$ $3.1 \mathrm{mg} / \mathrm{d} l, \mathrm{PaO}_{2} 95 \pm 12 \mathrm{mmHg}, \mathrm{O}_{2}$ saturation $95 \pm$ $12 \%$, ヘモグロビン $(\mathrm{Hb}) 9.0 \pm 0.9 \mathrm{~g} / \mathrm{d} l$ で, 糖尿病 $(\mathrm{DM})$ 合併例が 17 例含まれる。全例に血液検査で空腹時 血糖 $(\mathrm{FPG}), \mathrm{HbA1c}$, 脂質を測定した。自律神経機能の 評価のために定量性があり，有用性の報告されている心 電図 100 心拍の $\mathrm{R}-\mathrm{R}$ 間隔変動係数 $(\mathrm{CV})$ を測定し た ${ }^{8 \sim 10)}$. 動脈血ガス分析の結果と $\mathrm{Hb}$ 值から表 1 に示し た式で動脈血酸素含量 $\left(\mathrm{O}_{2}\right.$ content $)$ を算出した。また PVD の評価のために 1)問診で Fontaine 分類に基づく 自覚症状, 2)触診で㯟下動脈, 足背動脈, 後頸骨動脈の 拍動の有無, 3) 上腕/足関節部の収縮期血圧の比 (API), 4)下腿, 足部の単純 X線による動脈石灰化（中膜石灰化 症, MAC) の有無, を各々調べた。

$\mathrm{TCPO}_{2}$ 測定は経皮 $\mathrm{PO}_{2}$ モニタ 8000 (コーケンメディ カル社）を用いて，すでに報告した方法で測定した ${ }^{6,7)}$. すなわち測定条件は室温 $22 \sim 26^{\circ} \mathrm{C}$, センサー加温 $45^{\circ} \mathrm{C}$ と し, 安静仰臥位で第 $1 \cdot 2$ 趾の付け根から $2.5 \mathrm{~cm}$ 上方の 足背に $\mathrm{PO}_{2}$ センサを両面テープで固定し, 約 20 分後に レコーダに記録された值がほぼ一定した時点での酸素分 圧 (単位は $\mathrm{mmHg}$ ) を求めた。測定は原則として右足を 用いたが，左側にのみ PVD 症状を認める場合は左足で 測定した.

以下デー夕はすべて平均士標準偏差で表し, 統計学的 有意差検定は 2 群間比較は T-test， 3 群以上の比較には
表 1 Correlation coefficient between $\mathrm{TCPO}_{2}$ and various parameters in control, hemodialysis non-DM and DM subjects.

\begin{tabular}{lrrr}
\hline & & \multicolumn{2}{c}{ Hemodialysis } \\
\cline { 3 - 4 } \multicolumn{1}{c}{ Parameter } & Control & non-DM & \multicolumn{1}{c}{ DM } \\
\hline Age & $-0.34^{*}$ & $-0.54^{* * *}$ & -0.27 \\
Duration of HD & & 0.14 & $-0.40^{*}$ \\
BMI & -0.02 & -0.20 & 0.28 \\
FPG & -0.04 & -0.21 & -0.35 \\
HbA1c & -0.05 & 0.14 & -0.28 \\
CHO & -0.05 & -0.02 & 0.07 \\
TG & -0.11 & -0.01 & -0.10 \\
HDL-C & 0.11 & 0.07 & 0.11 \\
Cr & -0.09 & 0.20 & 0.23 \\
BUN & 0.05 & 0.10 & 0.16 \\
MABP & -0.12 & 0.05 & 0.06 \\
API & -0.03 & $0.29^{*}$ & -0.18 \\
CV & 0.19 & -0.05 & $0.40^{*}$ \\
Hb & 0.05 & 0.16 & $0.42^{*}$ \\
$\mathrm{O}_{2}$ content & & 0.25 & $0.49^{* *}$ \\
\hline
\end{tabular}

${ }^{*} \mathrm{p}<0.05,{ }^{* *} \mathrm{p}<0.01,{ }^{* * *} \mathrm{p}<0.001$

Abbreviation, MABP ; mean arterial blood pressure, API ; ankle/brachial pressure index, $\mathrm{CV}$; $\mathrm{R}-\mathrm{R}$ interval variation, $\mathrm{Hb}$; hemoglobin $\mathrm{O}_{2}$ content $=0.0031 \times \mathrm{PO}_{2}+\left[1.39 \times \mathrm{Hb} \times \mathrm{O}_{2}\right.$ saturation $] /$ 100

Scheffe の多重比較検定，頻度の差は $\chi^{2}$ 検定を用いた。

\section{結果}

1. $\mathrm{C}$ 群と $\mathrm{HD}$ 群の $\mathrm{TCPO}_{2}$

C群の $\mathrm{TCPO}_{2}$ は $68 \pm 12 \mathrm{mmHg}$ で, $50 \mathrm{mmHg}$ 以下 は2 例 $(6 \%)$ であった。一方 $\mathrm{HD}$ 群の $\mathrm{TCPO}_{2}$ は $52 \pm$ $12 \mathrm{mmHg}$ とC群より $24 \%$ 低く, その差は有意であった。 また $50 \mathrm{mmHg}$ 以下は HD 群では 30 例（46\%）と半数 近くに認めた。図に両群の $\mathrm{TCPO}_{2}$ をプロットした。 $\mathrm{HD}$ 群は糖尿病の有無により有意差があったため, non-DM 群とDM群に分けた。 HD 群では non-DM 群でも $\mathrm{TCPO}_{2}$ は $54 \pm 11 \mathrm{mmHg}(20 \sim 74)$ とC群より有意に低 く, $50 \mathrm{mmHg}$ 以下は 17 例(35\%) に認めた。一方 DM 群では $\mathrm{TCPO}_{2}$ は $45 \pm 13 \mathrm{mmHg}(17 \sim 63)$ と non-DM 群よりさらに低く, $50 \mathrm{mmHg}$ 以下は 17 例中 13 例 $(76 \%)$ と半数以上を占めた。

\section{2. $\mathrm{TCPO}_{2}$ 低下の危険因子}

C 群, $\mathrm{HD}$ 群の $\mathrm{TCPO}_{2}$ と各パラメータとの相関係数を 表 1 に示した.HD 群は non-DM 群，DM 群に分けた。 C 群では年齢とは有意な負の相関を認めたが, 他の因子 とは相関はなかった。C群では半数以上で動脈血採取は 行っていないため, $\mathrm{O}_{2}$ content と $\mathrm{TCPO}_{2}$ の相関はみて 


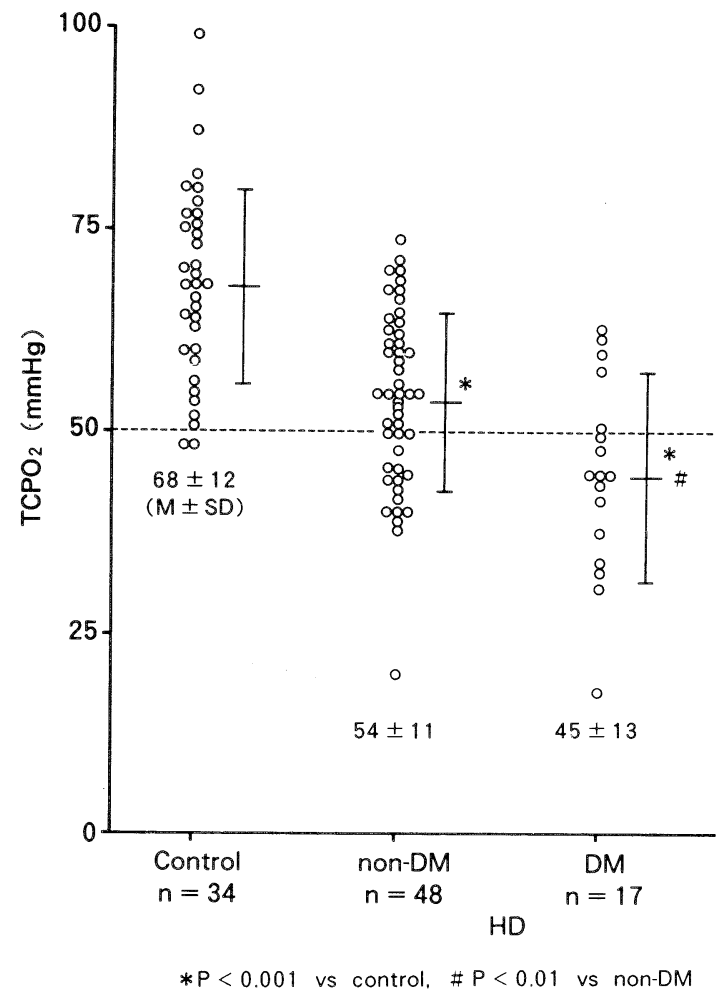

図 Transcutaneous oxygen tension in control and hemodialysis patients

いない.HD 群の non-DM 群では年齢と有意な負の相 関を，API と有意な正の相関を認め, $\mathrm{O}_{2}$ content とは有 意ではないが正に相関する傾向を認めた。しかし他の項 目とは有意な相関はなかった。DM群では透析罹病歴と 有意な負の相関を, $\mathrm{CV}, \mathrm{Hb}, \mathrm{O}_{2}$ content とは有意な正 の相関を認め, 年齢, FPG, HbAlc とは負に相関する傾 向を認めた。なお DM 群は non-DM 群と比べ, CV は 有意に低かったが $(1.0 \pm 0.7 \%$ VS $2.2 \pm 1.4 \%, \mathrm{p}<$ $0.001), \mathrm{Hb}, \mathrm{O}_{2}$ saturation, $\mathrm{O}_{2}$ content は有意差はな かった。自律神経障害や貧血に伴う $\mathrm{O}_{2}$. content $の$ 低下 は $\mathrm{DM}$ 群の $\mathrm{TCPO}_{2}$ 低下の危険因子と考元られた。

\section{3. $\mathrm{HD}$ 群の PVD の臨床診断と $\mathrm{TCPO}_{2}$ による評価}

表 2 に Fontaine 分類，末梢動脈拍動，API, MACの 有無から判定した $\mathrm{HD}$ 群の PVD の頻度と, $\mathrm{TCPO}_{2}$ の 関係を示した. Fontaine 分類では症状のない 0 度が 26 例， 1 度（冷感，しびれ） 24 例， 2 度（間欠性跛行） 4 例， 3 度（安静時下肢疼痛） 10 例， 4 度（潰瘍，壊疽） 1 例，で 1 度以上は 39 例（60\%）と半数以上であった。 $\mathrm{TCPO}_{2}$ は 0 度が $55 \pm 11 \mathrm{mmHg}, 1$ 度以上の有症状例は $50 \pm 12 \mathrm{mmHg}$ と有意差はなかった。しかし 2 度以上の 症例は 15 例 (23\%) で $\mathrm{TCPO}_{2}$ は $45 \pm 12 \mathrm{mmHg}$ であり，
表 $2 \mathrm{TCPO}_{2}$ in subjects without or with peripheral vascular disease (PVD). Clinical diagnosis of PVD is depends on the criteria listed on this table.

\begin{tabular}{|c|c|c|c|c|}
\hline \multirow[b]{2}{*}{ Criteria of PVD } & \multicolumn{2}{|c|}{$\operatorname{PVD}(+)$} & \multicolumn{2}{|c|}{$\mathrm{TCPO}_{2}$} \\
\hline & $n$ & $(\%)$ & $\operatorname{PVD}(-)$ & $\operatorname{PVD}(+)$ \\
\hline Fontaine $(1,2,3,4)$ & 39 & $(60)$ & $55 \pm 11$ & $50 \pm 12$ \\
\hline Fontaine $(2,3,4)$ & 15 & (23) & $54 \pm 11$ & $45 \pm 12^{*}$ \\
\hline Pulseless & 28 & (43) & $55 \pm 11$ & $47 \pm 12^{*}$ \\
\hline $\mathrm{API} \leqq 0.8$ & 9 & (14) & $53 \pm 12$ & $46 \pm 12$ \\
\hline $\operatorname{MAC}(+)$ & 31 & $(48)$ & $55 \pm 10$ & $49 \pm 14$ \\
\hline
\end{tabular}

${ }^{*} \mathrm{p}<0.01$ vs PVD $(-)$

Abbreviation, API ; ankle/brachial pressure index,

MAC ; medial arterial calcification.

1 度以下の例より有意に低值であった。なお non-DM 群 は, Fontaine 0 度 21 例, 1 度 18 例, 2 度 3 例, 3 度 6 例で, DM 群では 0 度 5 例, 1 度 6 例, 2 度 1 例， 3 度 4 例, 4 度 1 例で, 下肢の自覚症状には DM の有無で有 意な差はなかった。

触診により両側の膝下，後頸骨，足背動脈のいずれか の拍動が欠損していた症例は 28 例（43\%）であった。 $\mathrm{TCPO}_{2}$ は拍動欠損例が $47 \pm 12 \mathrm{mmHg}$ で，非欠損例の $55 \pm 11 \mathrm{mmHg}$ より有意に低值であった。な抢 DM 群で 13 例 $(76 \%)$ ， non-DM 群では 15 例 (31\%) に動脈拍動 の欠損を認め, DM 群の方が高頻度であった $(\mathrm{p}<$ 0.005)。このことから DM群では閉塞性動脈硬化症 (ASO) の頻度も non-DM 例より高いものと考えられ た。

一般に $\mathrm{API} \leqq 0.8$ を ASO の診断基準としている報告 が多いが，HD 群では $\mathrm{API} \leqq 0.8$ は 9 例 (14\%) であっ た. $\mathrm{API} \leqq 0.8$ の 9 例の $\mathrm{TCPO}_{2}$ は $46 \pm 12 \mathrm{mmHg}$ とやや 低かったものの, API >0.8 の例と比べ有意差はなかっ た. API と DM の関係は, DM 群 $1.08 \pm 0.06 \mathrm{mmHg}$, non-DM 群 $0.99 \pm 0.23 \mathrm{mmHg}$ で DM 群がやや APIが高 值であったが有意でなかった。

MACを認めた症例は 31 例 (48\%) であったが, $\mathrm{TCPO}_{2}$ はAC (一) 例が $55 \pm 10 \mathrm{mmHg}, \mathrm{MAC}(+)$ 例 が $49 \pm 14 \mathrm{mmHg}$ と有意差はなかった。な押 DM 患者 では 17 例中 16 例 $(94 \%)$ とほとんどの症例に MACを 認めた。一方 non-DM 群では 48 例中 15 例（31\%）に MAC を認めたが，有意に DM 群で下肢の動脈石灰化率 は高かった $(\mathrm{p}<0.001)$. DM 群で ASO の頻度が高い にも拘わらず APIがやや高かった原因には, 動脈石灰化 が高頻度であったためかもしれない.

\section{考察}

従来，末梢循環の評価法として自覚症状による 
Fontaine 分類, 未梢動脈拍動の触知, API 測定, サー モグラフィー, 指先容積脈波, ドップラー血流計, RI 血 流検查などが非侵襲的方法として利用されてき た ${ }^{11 \sim 13)}$. しかしいずれも半定量的な評価法であり，自律 神経障害による AV shunt 発達例のように無効血流が増 加している例では評価が困難である．また血管病変があ る程度進行しないと異常を検出できない可能性もある.

今回，下肢皮膚の酸素欠乏状態を非侵襲的，定量的に評 価する方法として $\mathrm{TCPO}_{2}$ を測定した。本方法はすでに 血管外科領域では未梢血管障害の診断や切断部位決定, 術後の効果判定に用いられ有用性が確立された方法であ り，再現性にも優れた検査法である ${ }^{1-7)} . \mathrm{TCPO}_{2}$ は 1）分 節的に測定すると血管閉塞部位の末梢ほど低值であり,

2）駆血により $10 \mathrm{mmHg}$ 以下に低下し, 解除により回復 する，3） $\mathrm{PGE}_{1}$ や $\mathrm{EPA}$ などの血流改善剤の投与で上昇 する, などから虚血の程度を反映して変動することも確 認している ${ }^{14,15)}$ 。すでに糖尿病患者の下肢虚血の評価法 として $\mathrm{TCPO}_{2}$ 測定の有用性を報告するとともに，PVD の判定の基準值として $50 \mathrm{mmHg}$ が適当であることを報 告してきた ${ }^{6,7)}$. そこで今回は, $\mathrm{TCPO}_{2}$ を指標として透析 患者の PVD の頻度, 臨床的特徴を調べるとともに, 他 の臨床診断による PVD の判定がどの程度 $\mathrm{TCPO}_{2}$ の低 下を反映しているのかを調べた。その結果, HD 群では $\mathrm{TCPO}_{2}$ が $50 \mathrm{mmHg}$ を基準値とすると $\mathrm{HD}$ 群では $46 \%$ に異常者を認めた. HD 群を DM の有無で分けると非 DM 群では 35\%に異常を認め, DM 群では $76 \%$ と半数 以上に異常を認めた。DM 群では下腿動脈石灰化や末梢 動脈拍動欠損の頻度が有意に高いことから, 下肢の動脈 硬化性変化ないしは ASO の頻度が非 DM 群より多いこ とが推測される。また DM 群では動脈病変に加え, 細小 血管障害や自律神経障害の合併も $\mathrm{TCPO}_{2}$ 低下を促進し た可能性が示唆された ${ }^{16 \sim 19)}$.さらに DM 群では動脈血の $\mathrm{Hb} や \mathrm{O}_{2}$ content と $\mathrm{TCPO}_{2}$ も有意な正の相関を認め た。組織の酸素供給には血流因子と同時に, 動脈血の酸 素運搬能も重要な因子である.酸素運搬能は, $\mathrm{O}_{2}$ content と血流の積で規定される. $\mathrm{O}_{2}$ content は表 1 の式に示 したように, $\mathrm{Hb}$ と酸素飽和度の影響を強く受け, 貧血に 伴う $\mathrm{O}_{2}$ content の低下も $\mathrm{TCPO}_{2}$ 低下の促進因子と考元 られた。最近, $\mathrm{Hb}$ が $3 \mathrm{~g} / \mathrm{d} l$ の再生不良性貧血患者で $\mathrm{ASO}$ を伴わないにも拘わらず $\mathrm{TCPO}_{2}$ が $35 \mathrm{mmHg}$ に低 下した症例を経験している. 本例は輸血により貧血が改 善すると $\mathrm{TCPO}_{2}$ も $65 \mathrm{mmHg}$ まで改善した. $\mathrm{HD}$ 患者 でも貧血の著明な例に貧血を改善した場合, $\mathrm{TCPO}_{2}$ が可 逆的に改善するのか否か興味がもたれる.この点に関し ては, 現在検討中である. 一方, non-DM 群では加齢と $\mathrm{API}$ の低下が $\mathrm{TCPO}_{2}$ 低下の危険因子であった. 多分こ
れらの因子以外にも, 細動脈硬化や $\mathrm{Hb}-\mathrm{O}_{2}$ 解離能の変 化，レオロジー因子，局所の酸素消費，皮膚の肥厚や性 状の変化なども $\mathrm{TCPO}_{2}$ に影響している可能性があろ $3^{20 \sim 22)}$.

各種臨床診断に基づく PVD の有無と $\mathrm{TCPO}_{2}$ の関係 も検討したが, $\mathrm{TCPO}_{2}$ 低下と有意な相関を認めたのは, 自覚症状では Fontaine 2 度以上，または末梢動脈拍動 の欠損であった. Fontaine 1 度の冷感やしびれは ASO を必ずしも反映するとは限らず，末梢神経障害との鑑別 が必要であろう。また HD 患者には動脈石灰化のために APIが見かけ上高くなることがある (pseudohypertension $)^{23)}$. API も低い場合は明らかに異常と考えられ るが，高い場合には判定が難しいようである，下肢が虚 血状態であるか否かは，これら PVD の臨床診断に加え て $\mathrm{TCPO}_{2}$ を指標とした評価を同時に行うことで，総合 的な評価が必要であろう. 以上, 透析患者では $\mathrm{TCPO}_{2}$ が 健常者より有意に低く, 本検査は透析患者の未梢循環障 害の非侵襲的，定量的な評価に有用と考えられた。透析 患者の $\mathrm{TCPO}_{2}$ 低下には加齢, 糖尿病や ASO の合併と ともに, DM 群では特に自律神経障害, $\mathrm{O}_{2}$ content $の$ 低 下が $\mathrm{TCPO}_{2}$ 低下の危険因子と考えられた。

謝辞：稿を終えるにあたり，本論文の御校閲を賜りました 滋賀医科大学第 3 内科, 繁田幸男教授, 柏木厚典講師, なら びに御協力頂いた本院透析室, 西浦多恵子婦長以下スタッフ の皆さんに深謝いたします。

\section{文献}

1) Hauser CJ, Klein SR, Mehringer M, Appel $P$, Shoemaker WC : Assessment of perfusion in the diabetic foot by regional transcutaneous oximetry. Diabetes 33 : 527-531, 1984

2) Rooke TW, Osmundson PJ : Theinfluence of age, sex, smoking, and diabetes on lower limb transcutaneous oxygen tension in patients with arterial occlusive disease. Arch Intern Med 150:129-132, 1990

3）伊藤勝朗，応儀成二：経皮酸素分圧測定法，末梢血 管診断の無侵襲診断法, (塩野谷恵彦, 大原 到, 坂 口周吉編), p 112-135, 永井書店, 大阪, 1983

4) Kram HB, Appel PL, Schoemaker WC : Comparison of transcutaneous oximetry, Vascular hemodynamic measurements, angiography, and clinical findings to predict the success of peripheral vascular reconstruction. Am J Surgery 155 : 551-558, 1988 
5) Wyss CR, Matsen FA, Simmons CW, Burgess EM : Transcutaneous oxygen tension measurements on limbs of diabetic and nondiabetic patients with peripheral vascular disease. Surgery $95: 339-346,1984$

6）紀田康雄，柏木厚典，瀧 秀樹，日高秀樹，吉川隆 一，繁田幸男：経皮酸素分圧測定による糖尿病患者 下肢虚血の評価と有用性. 糖尿病 $36 ： 195-201,1992$

7）紀田康雄，柏木厚典，瀧 秀樹，中川浩子，日高秀 樹，吉川隆一，繁田幸男：NIDDM の下肢経皮酸素 分圧低下の危険因子に関する検討。糖尿病 36： 917-922，1993

8）紀田康雄, 吉川隆一，安田 斎，畑中行雄，小林伸 行, 山下真木夫，繁田幸男：糖尿病患者における各 種自律神経機能検查法の比較検討。糖尿病 27 : 671-677, 1984

9) Ewing DJ, Borsey DQ, Bellavere F, Clark BF : Cardiac autonomic neuropathy in diabetes: Comparison of measures of RR interval variation. Diabetologia $21: 18-24,1981$

10) Bennett T, Fentem PH, Fitton D, Hampton JR, Hosking DJ, Riggott PA : Assessment of vagal control of the heart in diabetes: measure of RR interval variation under different conditions. $\mathrm{Br}$ Med J 3 : 25-28, 1977

11）坂口周吉，神谷 隆：末梢動脈硬化症，動脈硬化症 の新しい診断 (五島雄一朗, 後藤由夫編), p 202-211, 医薬ジャーナル社，東京，1985

12）土光荘六：Impedance plethysmography について, 末梢血管診断の無侵襲診断法（塩野谷恵彦，大原 到, 坂口周吉編), p 60-71, 永井書店, 大阪, 1983

13）久保敦司：RI 検查法 末梢血管診断の無侵襲診断 法(塩野谷恵彦, 大原 到, 坂口周吉編), p 136-144, 永井書店，大阪，1983

14）紀田康雄, 柏木厚典, 池淵元祥, 繁田幸男 : 糖尿病 患者の下肢虚血に対する $\mathrm{PGE}_{1}$ 注入療法，経皮酸素
分圧を用いた diabetic foot の観察と $\mathrm{PGE}_{1}$ の急性 効果. 現代医療 24：2883-2887，1992

15）紀田康雄, 柏木厚典, 繁田幸男：イコサペント酸 (EPA) に上る糖尿病患者の下肢循環障害の治療, 経 皮酸素分圧を用いた有用性の検討. 基礎と臨床 27： 3249-3256, 1993

16）高井孝二, 山本邦宏, 佐藤公司, 坂本美一, 松田文 子, 葛谷 健: 糖尿病患者に扮ける足背静脈酸素分 圧の上昇, 糖尿病性神経障害の一徵候としての動静 脈シャント量の増加. 糖尿病 27 ：1059-1065， 1984

17) Kida Y, Kashiwagi A, Nishio Y, Kodama M, Abe $N$, Shigeta $Y$ : Is difference of arterial and venous oxygen content a possible marker for diabetic foot. Diabetes Care 11 : 515-516, 1988

18) Boulton AJM, Scarpeilo JHB, Ward JD : Venous oxygenation in the diabetic neuropathic foot: Evidence of arteriovenous shunting? Diabetologia $22: 6-8,1982$

19) Uccioli L, Mancini L, Giordano A, Solini A, Magnani P, Manto A, Cotroneo P, Greco AV, Ghirlanda G : Lower limb arterio-venous shunts, autonomic neuropathy and diabetic foot. Diab Res Clin Pract 16 : 123-130, 1992

20) Robert SG, Gerald SL: Skin manifestation of diabetes mellitus. In "Diabetes Mellitus" ed Ellenberg M, Rifkin H, p 879-893, Medical Examination Publishing Co. New York, 1983

21) Kilo C, Volger N, Williamson JR : Muscle capillary basement membrane related to aging and to diabetes mellitus. Diabetes $21: 881-898,1972$

22）磯貝行秀, 池本 卓：血液レオロジー・・凝固, 糖尿 病学 (垂井清一郎, 葛谷 健編), p 222-230, 朝倉書 店，東京，1990

23) Oster JR, Materson BJ : Pseudohypertension : A diagnostic dilemma. J Clin Hypertens 2 : 307-313, 1986 